\title{
Structural properties of fluorinated amorphous carbon films
}

\author{
X. Wang, H. R. Harris, K. Bouldin, H. Temkin, and S. Gangopadhyaya) \\ Department of Physics and Electrical Engineering, Texas Tech University, Lubbock, Texas 79409
}

M. D. Strathman and M. West

Thin Film Analysis, Inc., Sunnyvale, California 94086

(Received 8 February 1999; accepted for publication 21 September 1999)

\begin{abstract}
Fluorinated amorphous carbon films have been deposited in a plasma-enhanced chemical vapor deposition system, and the optical properties examined by Fourier transform infrared and ultraviolet-visible absorption spectroscopy. The infrared absorption spectra in the region from 1000 to $1800 \mathrm{~cm}^{-1}$ were resolved into ten peaks, which were assigned to various carbon-fluorine and carbon-carbon vibration modes. A relationship between the optical band gap and the aromatic carbon $\left(s p^{2}\right)$ concentration is demonstrated. (C) 2000 American Institute of Physics.

[S0021-8979(00)00101-8]
\end{abstract}

Fluorinated amorphous carbon $\left(a-\mathrm{CF}_{x}\right)$ deposited by plasma enhanced chemical vapor deposition (PECVD) is one of the most promising materials for interlevel dielectric films in ultralarge scale integration technology. ${ }^{1,2}$ However, the thermal stability of $a-\mathrm{CF}_{x}$ films in subsequent processing steps, which can reach $400{ }^{\circ} \mathrm{C}$, remains an unresolved problem in interconnect implementation.

Structural properties of fluorinated amorphous carbon films are controlled by processing conditions such as deposition temperature, ion bombardment, and gas flow ratios. ${ }^{2}$ Since thermal stability depends on the structure of the film, it is also controlled by these parameters. This communication describes the use of Fourier transformed infrared (FTIR) absorption spectroscopy and ultraviolet-visible (UV-visible) absorption to investigate the structural properties of the $a-\mathrm{CF}_{x}$ films and their relationship to thermal stability. The bonding configurations have been identified from the infrared absorption spectra, and a strong correlation can be established between the aromatic carbon concentration and the optical band gap.

The deposition of $a-\mathrm{CF}_{x}$ films was performed in a parallel-plate, capacitively coupled, $13.5 \mathrm{MHz}$ PECVD system (base pressure $10^{-7}$ Torr). The substances were placed on a heated chuck (grounded electrode), and the temperature varied from 50 to $480{ }^{\circ} \mathrm{C}$. The films were prepared using $\mathrm{C}_{2} \mathrm{H}_{2}$ and $\mathrm{CF}_{4}$ source gases. Samples were deposited on quartz for UV-visible absorption measurements and on $\mathrm{Si}(100)$ for FTIR measurements. The total pressure and $\mathrm{rf}$ power remained constant, while the deposition temperature and gas flow ratios $\left(\mathrm{CF}_{4} /\left(\mathrm{CF}_{4}+\mathrm{C}_{2} \mathrm{H}_{2}\right)\right)$ were the variable process parameters. To determine the concentrations of fluorine, hydrogen, and oxygen, the films were analyzed by Rutherford backscattering (RBS). The IR spectra were recorded using a Perkin-Elmer model 1600 spectrometer with $8 \mathrm{~cm}^{-1}$ resolution, and a Shimatzu model 2400PC UV-visible spectrometer was used to obtain optical absorption data. The op-

\footnotetext{
a) Author to whom correspondence should be addressed; electronic mail: Shubhra.Gangopadhyay@ttu.edu
}

tical absorption spectra were analyzed to obtain the optical band gap using the Tauc method. ${ }^{3}$

The infrared absorption spectra of $a-\mathrm{CF}_{x}$ films were recorded in the range of $400-4000 \mathrm{~cm}^{-1}$ and corrected for the substrate absorption. Since the strongest IR absorption bands were present in the $1000-1900 \mathrm{~cm}^{-1}$ region, analysis of these bands was the focus of our investigation. The samples chosen for present study have hydrogen concentration less than 10 at. \%. This was done to eliminate strong bending mode vibrations of various carbon-hydrogen bonds in the $1200-1500 \mathrm{~cm}^{-1}$ region of the spectra.

Figure 1 provides the IR absorption spectra between 1000 and $1800 \mathrm{~cm}^{-1}$ for four $a-\mathrm{CF}_{x}$ films. The first two spectra represent films deposited at high temperature, but with different gas flow ratios (GFRs). The last two spectra, when grouped with the second, represent films deposited with the same GFR, but varying temperatures. The strong IR absorption in this region originates from carbon-fluorine and carbon-carbon vibration modes. To reveal the exact structure of $a-\mathrm{CF}_{x}$ films, these IR spectra were fitted to Gaussian distributions. Because of the presence of many vibration modes, resolution of the spectra into distinct peaks was not straightforward. However, when the spectra of the films deposited at temperatures of $400^{\circ} \mathrm{C}$ and above were analyzed, the peaks from specific vibration modes were clearly distinguishable (see the top spectra in the Fig. 1), and the spectra could be resolved into ten peaks. These peak positions did not depend on the starting parameters and were reproducible within experimental uncertainty. Subsequent lowtemperature spectra could then be reliably resolved using the peak values of the high-temperature samples as starting points in the peak fitting process.

Our assignment of IR peaks to various vibration modes was based on the available literature ${ }^{4-7}$ and changes in the total absorption of each peak with processing parameters. Five peaks were identified in the region from 1000 to 1400 $\mathrm{cm}^{-1}$ associated with the following: $-\mathrm{CF}_{2}$ symmetric mode $\left(1100 \mathrm{~cm}^{-1}\right),-\mathrm{CF}_{2}$ asymmetric mode $\left(1200 \mathrm{~cm}^{-1}\right), \mathrm{F}$-aryl vibration mode $\left(1150\right.$ and $\left.1260 \mathrm{~cm}^{-1}\right)$, and $\mathrm{C}-\mathrm{F}$ stretch mode $\left(1340 \mathrm{~cm}^{-1}\right)$. The $a-\mathrm{CF}_{x}$ films prepared at room tem- 


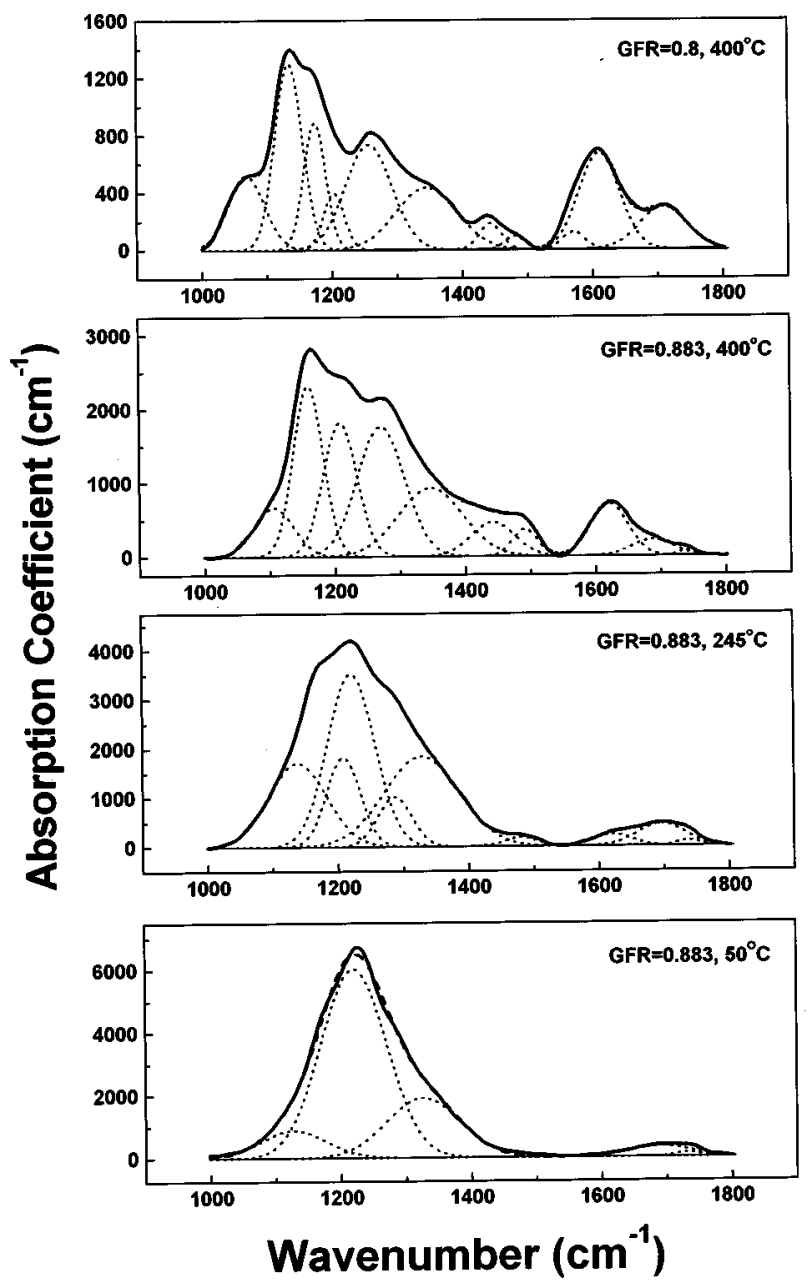

FIG. 1. IR spectra of films at different gas flow ratios (top two spectra) and deposition temperatures (bottom three spectra). The solid lines are the experimental spectra. The dotted lines are the resolved Gaussian peaks. The dashed lines are the summation of the resolved Gaussian peaks.

perature were soft, polymer-like, and transparent. These films consisted mainly of $-\mathrm{CF}_{2}$ chains, identified by the 1200 $\mathrm{cm}^{-1}$ peak, in agreement with other studies. ${ }^{6,7}$ The 1340 $\mathrm{cm}^{-1}$ peak has been assigned to $\mathrm{C}-\mathrm{F}$ stretch vibration by several groups. ${ }^{5,6}$

Between 1400 and $1650 \mathrm{~cm}^{-1}$, three peaks associated with aromatic ring with attached fluorine were observed located at 1460,1495 , and $1620 \mathrm{~cm}^{-1}$. The aromatic ring vibration without fluorine attachment (as in graphite) is not IR active. Assignment of the 1150 and $1260 \mathrm{~cm}^{-1}$ peaks to $\mathrm{F}$-aryl vibration is based on the observation that the area of these peaks changes with various processing parameters, similar to the change in the area of the $1620 \mathrm{~cm}^{-1}$ peak. Figure 2 shows the positions of the 1150 and $1620 \mathrm{~cm}^{-1}$ peaks as a function of the fluorine concentration in the films. With an increase in fluorine concentration there is a linear shift to higher frequency of both of these peaks. This shift to higher frequency may be due to an increase in the number of fluorine atoms bonded to aromatic carbon. Similar shifts have been reported for aromatic ring stretching vibrations for substituted benzene. ${ }^{4}$ Comparable trends in frequency shifts for the 1150 and $1620 \mathrm{~cm}^{-1}$ peaks verified the assumption that both peaks originate from the same structure.

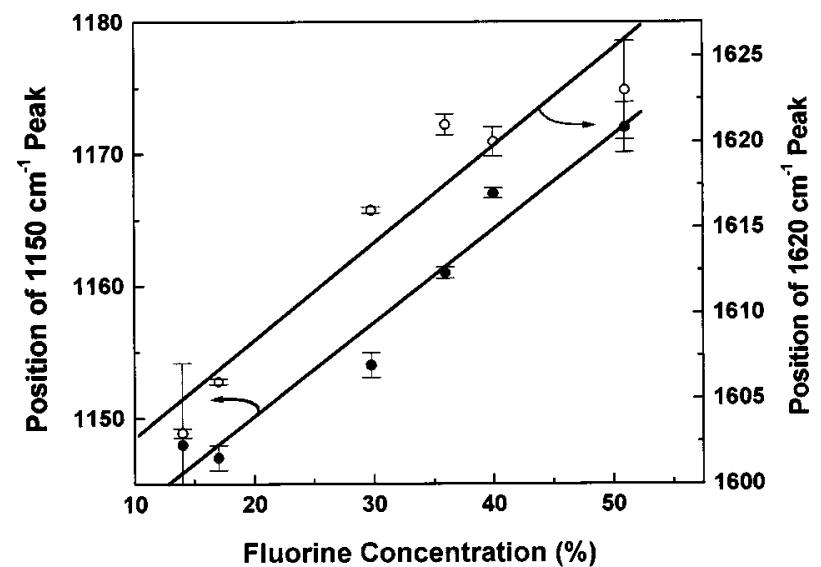

FIG. 2. Frequency shift of the 1620 and $1150 \mathrm{~cm}^{-1}$ peaks as a function of fluorine content.

It is interesting to note that for the sample prepared at $400{ }^{\circ} \mathrm{C}$ and with a GFR of 0.8 (see Fig. 1), where most of the carbon was bonded in aromatic ring structures, the $\mathrm{F}$-aryl vibration mode was split into two peaks at 1133 and 1174 $\mathrm{cm}^{-1}$. Also, a peak emerges at $1570 \mathrm{~cm}^{-1}$. This peak may be attributed to aromatic ring vibration without fluorine attachment, which becomes IR active due to the increase in disorder in the film.

In the region between 1650 and $1850 \mathrm{~cm}^{-1}$, three peaks were found at 1690,1735 , and $1830 \mathrm{~cm}^{-1}$. Carbonyl compounds give rise to strong bands in the $1550-1900 \mathrm{~cm}^{-1}$ region due to the stretching of the $\mathrm{C}=\mathrm{O}$ bonds. ${ }^{4}$ In order to verify if any of these three peaks were due to $\mathrm{C}=\mathrm{O}$ stretch vibration, $a-\mathrm{CF}_{x}$ films were prepared by adding small quantities of oxygen to the feed gases and by keeping other process parameters constant. For the sake of comparison, the areas of these peaks were normalized with respect to the $1620 \mathrm{~cm}^{-1}$ peak from aromatic ring vibration. Since the same process parameters were used for the deposition of the films, we believe that the microstructure and the oscillator strength of $\mathrm{C}=\mathrm{C}$ and $\mathrm{C}=\mathrm{O}$ bonds did not change in this experiment. This validates the normalization of these peaks with $1620 \mathrm{~cm}^{-1}$ peak. In Fig. 3, the normalized areas of these peaks have been plotted as a function of the ratio of the oxygen flow to the total gas flow. The area of 1690 and 1830 $\mathrm{cm}^{-1}$ peaks increased considerably, while the area of the $1735 \mathrm{~cm}^{-1}$ peak remained constant, as the oxygen gas flow increased. This indicates that the 1690 and $1830 \mathrm{~cm}^{-1}$ peaks arise from the $\mathrm{C}=\mathrm{O}$ stretch vibration. A small peak found at $1735 \mathrm{~cm}^{-1}$ may be associated with olefinic carbon with attached fluorine $\left(\mathrm{C}=\mathrm{CF}_{2}\right)$. The relatively small area of this peak indicates the presence of $\mathrm{C}=\mathrm{CF}_{2}$ in a very small concentration, probably as termination groups of the $-\mathrm{CF}_{2}$ chains.

As mentioned before, $a-\mathrm{CF}_{\mathrm{x}}$ films prepared at room temperature consisted mainly of $-\mathrm{CF}_{2}$ chains (see Fig. 1). As the deposition temperature increased, the absorption from fluorine atoms bonded to the aromatic ring $(\mathrm{F}-$ aryl $)$ increased at the cost of $-\mathrm{CF}_{2}$ chains. The concentration of aromatic carbon is the primary indicator of the amount of crosslinking, which determines the thermal stability of the films. ${ }^{2}$ Another 

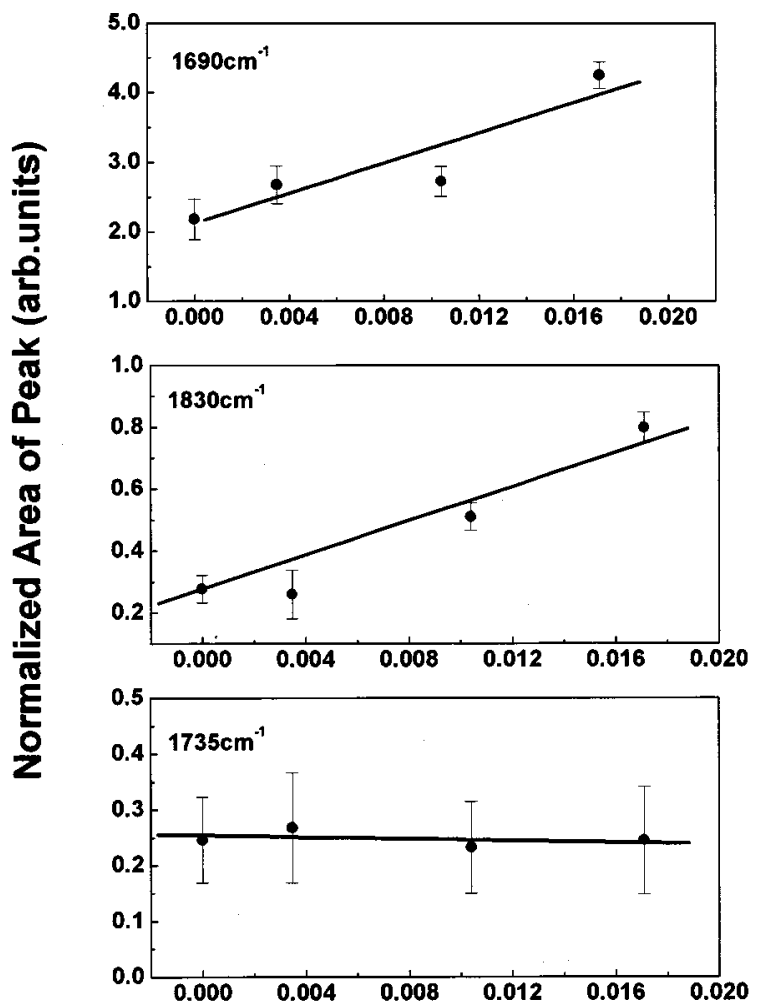

Ratio of Oxygen Flow to Total Gas Flow

FIG. 3. Variation in the area of the 1690,1735 , and $1830 \mathrm{~cm}^{-1}$ peaks with the ratio of oxygen to total gas flow.

indicator of the amount of crosslinking is the optical band gap. An increase in the concentration of aromatic $\left(s p^{2}\right.$ bonded) carbon results in a decrease in the optical band gap. ${ }^{8}$ Hence it is worthwhile to correlate the optical band gap of $a-\mathrm{CF}_{x}$ films prepared under various deposition conditions with the concentration of aromatic carbon.

The area of the $1620 \mathrm{~cm}^{-1}$ peak plotted as a function of the optical band gap does not show any clear trend. Since this peak represents only the aromatic carbon bonded to fluorine, it does not measure the total concentration of aromatic carbon and thereby the total amount of crosslinking. In order to obtain a better measure of the total concentration of aromatic carbon, we normalized the IR absorption spectra of $a-\mathrm{CF}_{x}$ films to the carbon-fluorine peak present in the $1000-1400 \mathrm{~cm}^{-1}$ region. This normalization is valid under the condition that there is no change in the oscillator strength of various $\mathrm{C}-\mathrm{F}$ modes with changing process parameters. Since we knew the fluorine concentration and atomic density of these samples from the RBS experiment, we calculated the oscillator strength of $a-\mathrm{CF}_{x}$ films prepared under various deposition conditions. The change in the oscillator strength with changing process parameters was found to be within experimental uncertainty. Figure 4 depicts the plot of the normalized area of the $1620 \mathrm{~cm}^{-1}$ peak as a function of the optical band gap for $a-\mathrm{CF}_{x}$ films prepared at various deposition temperatures and gas flow ratios. A linear increase in the area of the $1620 \mathrm{~cm}^{-1}$ peak with a decrease in the optical

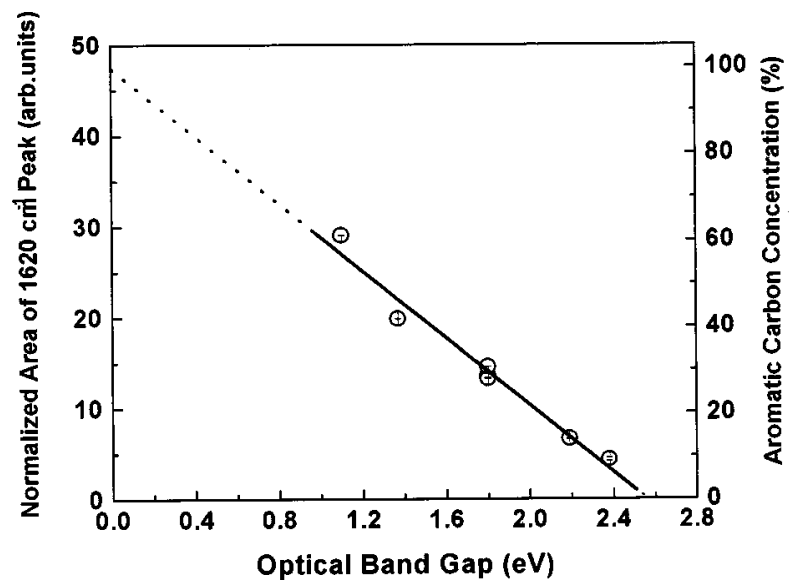

FIG. 4. Dependence of the optical band gap on the normalized area of the $1620 \mathrm{~cm}^{-1}$ peak.

band gap indicates that the normalized area of the $1620 \mathrm{~cm}^{-1}$ peak is directly related to the total amount of aromatic carbon, and hence to the amount of crosslinking in the film. Assuming that an optical band gap of zero corresponds to $100 \%$ aromatic (graphitic) carbon, the plot of \% aromatic carbon for the films is displayed in Fig. 4. Based on our study of the effect of deposition parameters on the thermal stability of $a-\mathrm{CF}_{x}$ films, we predict that a normalized area of $15 \pm 2 \mathrm{~cm}^{-2}$, or $30 \% \pm 5 \% s p^{2}$ aromatic carbon is necessary to achieve $400{ }^{\circ} \mathrm{C}$ thermal stability in $a-\mathrm{CF}_{x}$ films. It should be mentioned that this analysis is valid only for the films with the optical band gap $>1 \mathrm{eV}$. In highly disordered films with the optical band gap $<1 \mathrm{eV}$, the aromatic ring vibration without fluorine attachment becomes IR active. This makes the spectroscopic analysis difficult and less reliable.

In summary, we investigated fluorinated amorphous carbon films produced in a PECVD system that exhibit varying degrees of aromatic carbon, which is related to the degree of crosslinking. By assigning individual peaks in the FTIR absorption spectra to specific modes, and monitoring the changes of these modes with the change in deposition parameters, it has been found that the films with thermal stability at up to $400{ }^{\circ} \mathrm{C}$ have $30 \%$ aromatic carbon. Furthermore, a relationship between the optical band gap and the concentration of aromatic carbon has been established.

This work was supported by the National Science Foundation under Contract No. ECS-9614593.

\footnotetext{
${ }^{1}$ H. Kudo, S. Takeishi, R. Shinohara, and M. Yamada, Proceedings of the Dielectrics for ULSI Multilevel Interconnection Conference, Santa Clara, CA, 1997, ISMIC-222D, p. 85

${ }^{2}$ H. Yang, T. Nguyen, Y. Ma and S. T. Hsu, Proceedings of the Dielectrics for ULSI Multilevel Interconnection Conference, Santa Clara, CA, 1998, IMIC-333D, p. 38.

${ }^{3}$ J. Tauc, R. Grigorovici, and A. Vancu, Phys. Status Solidi 15, 627 (1966).

${ }^{4}$ N. B. Colthup, L. H. Daly, and S. E. Wiberley, Introduction to Infrared and Raman Spectroscopy (Academic, New York, 1964).

${ }^{5}$ H. Giegengack and D. Hinze, Phys. Status Solidi A 8, 513 (1971).

${ }^{6}$ H. Yokomichi and T. Hayashi, Appl. Phys. Lett. 72, 2704 (1998).

${ }^{7}$ S. Liu, S. Gangopadhyay, G. Sreenvias, S. S. Ang, and H. A. Naseem, Phys. Rev. B 55, 13020 (1997).

${ }^{8}$ J. Robertson, Prog. Solid State Chem. 21, 199 (1991).
} 